\title{
Teaching Physical Assessment and Disease Screening to Students in the Health Professions: A Focus in Pharmacy Education
}

\author{
Monica Zolezzi1 ${ }^{*}$, Oraib Abdallah ${ }^{1}$, Stella Major ${ }^{2}$, Diana White ${ }^{3}$, Yaw Owusu1, \\ Sowndramalingam Sankaralingam ${ }^{1}$ \\ ${ }^{1}$ College of Pharmacy, Qatar University, Doha, Qatar \\ ${ }^{2}$ Weill Cornell Medicine-Qatar, Qatar Foundation, Doha, Qatar \\ ${ }^{3}$ University of Calgary Qatar, Doha, Qatar \\ Email: *mzolezzi@qu.edu.qa
}

How to cite this paper: Zolezzi, M., Abdallah, O., Major, S., White, D., Owusu, Y. and Sankaralingam, S. (2016) Teaching Physical Assessment and Disease Screening to Students in the Health Professions: A Focus in Pharmacy Education. Health, 8, 1713-1725.

http://dx.doi.org/10.4236/health.2016.815166

Received: October 29, 2016

Accepted: December 4, 2016

Published: December 7, 2016

Copyright $\odot 2016$ by authors and Scientific Research Publishing Inc. This work is licensed under the Creative Commons Attribution International License (CC BY 4.0).

http://creativecommons.org/licenses/by/4.0/ (c) (i) Open Access

\begin{abstract}
Background: As pharmacists continue to transition into the provision of public health care, physical assessment and disease screening will become part of their everyday practice, in a similar manner that it has been for doctors and nurses. Objective: The aim was to describe the health assessment of undergraduate curricula across three disciplines involved in public health care and to explore the students' perceived training in a variety of health assessments. Method: Instructors of courses related to health assessment in medicine, nursing, and pharmacy colleges in Qatar were invited to participate in the curriculum review process. Students' perceived training in a variety of health assessments was assessed using a self-administered survey. Both descriptive and inferential statistics were used to analyze the survey responses. Results: A narrative description for the similarities and differences in the health assessment curricula across the three colleges was provided. Blood pressure, heart rate, and heart sounds were the health assessments that almost all students received training on, although there were differences in where the training was delivered. The health assessments that the students perceived having received least training on were measuring bone mineral density, blood cholesterol and international normalized ratio reported by only $37 \%, 41 \%$ and $44 \%$ of students, respectively. Conclusion: The study identified a close alignment between each of the health discipline's scope of practice and the health assessment content taught in each individual program. It also identified possible curricular gaps towards learning the skills of patient assessment that may need to be addressed.
\end{abstract}

\section{Keywords}

Health Assessment, Disease Screening, Pharmacy Practice, Health Professions Education 


\section{Introduction}

In order to address public health needs, many of today's health professions students are learning new skills that prepare them to improve access to primary health care, narrow health disparities, and advance prevention efforts in a collaborative manner. Pharmacists' accessibility and comprehensive training make them well positioned to address some of these unmet health care needs within their communities. As pharmacists continue to transition into more direct patient care roles and in the provision of public health care, patient assessment will become part of their everyday practice, in a similar manner that it has been for doctors and nurses. In fact, there are many functions of public health that can benefit from pharmacists' unique pharmacotherapy knowledge and expertise including chronic disease management, health promotion and preventative care such as, immunization, risk factor management, and lifestyle counseling [1] [2] [3]. As such, pharmacists are now expected to perform physical examinations (PEs), utilize point-of-care (POC) laboratory devices for health/disease screening (HDS), order and interpret laboratory tests to justify indication or appropriateness of medication use, to monitor for efficacy and tolerability of drug therapy, or to refer patients for further assessment when indicated [4] [5] [6] [7] [8].

The College of Pharmacy (CPH) at Qatar University (QU) offers a Canadian-accredited bachelor of science in pharmacy program. Current accreditation guidelines in North America require that the curriculum of first professional degrees in pharmacy includes instruction on patient assessment. The Association of Faculties of Pharmacy of Canada (AFPC) educational outcomes for Canadian-accredited pharmacy programs stipulate that graduates must be able to perform PE and HDS [9]. To ensure pharmacy students receive instruction in such skills, the Accreditation Council for Pharmacy Education (ACPE) standards require that curriculums include a patient assessment laboratory addressing PE techniques [10]. Also, the educational outcomes of the 2013 American Association of Colleges of Pharmacy (AACP) Center for the Advancement of Pharmaceutical Education (CAPE) call for students to be able to perform and evaluate aspects of patient physical assessment [11]. In a recent survey of colleges of pharmacy in the United States (US) published in 2014, 93 percent of colleges surveyed indicated that PE skills are taught within their respective curriculum [12].

In this article, we intend to describe and compare the PE and HDS assessment learning delivered in undergraduate curricula across disciplines involved in the provision of public health care (medicine, nursing, and pharmacy) in Qatar. The aim is to explore course content and the pedagogies utilized, as well as to describe commonalities and differences in the health assessment curricula among these three disciplines. In addition, the students' perceived training in a variety of health assessments will be explored to help educators identify potential curricular gaps that may need addressing. We used the term "health assessment" to simplify the text and include educational activities related to PE and HDS assessments.

\section{Methods}

\subsection{Curriculum Review}

Curriculum can be mapped in terms of what is intended, what is delivered, and what is 
assessed [13]. Intended curriculum is mapped based on program and course documents. We implemented mapping of the intended curriculum according to the following procedure:

1) Obtaining copies of course syllabi for each course related to health assessment delivered to obtain a BS in pharmacy, BS in nursing and an MD degree at $\mathrm{CPH}-\mathrm{QU}$, the University of Calgary in Qatar (UCQ), and Weill Cornell Medical College in Qatar (WCM-Q), respectively.

2) Extracting and summarizing the content, teaching methods and tools, timetabling and sequencing, and learning outcomes and student assessment in these courses.

3) Providing a narrative description of the similarities and differences in the health assessment curricula across the three degree programs.

4) Determining the relative number of course objectives linked to AFPC educational outcome elements (relevant only to pharmacy courses).

Department chairs and instructors of courses related to health assessment at the CPH-QU, UCQ and WCM-Q were invited to participate in the curriculum review process described above.

\subsection{Student Survey}

Data regarding students' perceived training in a variety of health assessments was extracted from the results of a survey investigating the same group of healthcare students' preparedness for the provision of cardiovascular risk assessment services. This survey was administered to $3 \mathrm{rd}$ and 4th-year students at the same participating colleges (CPH-QU, UCQ, and WCM-Q) during the 2014-2015 academic year. Students were eligible to participate if they had covered the cardiovascular therapeutics curricula and had been through at least one clinical (practical) placement. The questionnaire used in this survey was divided into four sections, of which only the results of Part 1 (describing the participating students' demographic information) and Part 2, sub-section 1 (describing the participating students' perceived training on a variety of health assessments) were used. The detailed survey method utilized in this data-feeding study is described elsewhere (manuscript under review by Pharmacy journal). The survey received ethics approval from QU Institutional Review Board and administrative approval from UCQ and WCM-Q.

The data extracted for inclusion in this article was analyzed using both descriptive and inferential statistics. Chi-square test for measuring the differences in health assessment training scores among the three cohorts of students was also used. The level of significance was set a priori at $\mathrm{p} \leq 0.05$.

\section{Results}

\subsection{Curriculum Mapping}

\subsubsection{The CPH Health Assessment Curricula}

Two sequential courses were identified in the pharmacy curriculum that were related to health assessment, namely PHAR361/362 which are designed to introduce second year 
pharmacy students to the various techniques and tools necessary to conduct PE and to monitor changes caused by common disease states and related drug therapy. These courses also aim to help the students interpret $\mathrm{PE}$ and laboratory findings and to evaluate patient information in order to understand the clinical status of the patient for the purpose of making decisions related to pharmacotherapy.

As described in Table 1, the course addresses the professional competencies of care-provider, communicator and professional as adopted and adapted for use in Qatar from the National Association of Pharmacy Regulatory Authorities (NAPRA) and AFPC [9] [14].

An anatomical system-based approach is used to deliver the content. For the most part, teaching is integrated with other courses which are also delivered using a system-based approach, such as "Pathophysiology", "Pharmacology", "Professional Skills", and "Laboratory Data" courses.

The course is delivered by physician-pharmacist collaboration using Blackboard ${ }^{\circledR}$ course management software. The physician focuses on teaching medical terminologies, anatomy, PE methods, techniques and the use of required tools or instruments, while the pharmacist teaches how information as a result of PE is used to understand the clinical status of the patient for the purpose of making decisions related to phar-

Table 1. Learning outcomes of the health assessment courses at $\mathrm{CPH}$.

Learning Objectives

At the completion of the two courses students will be able to:

1. Develop communication techniques to facilitate efficient and effective patient encounters.

2. Obtain and evaluate relevant history from the patient, and/or charts, caregivers and health care professionals.

3. Understand medical terminologies related to $\mathrm{PE}$, case histories and investigations in order to determine the clinical status of patients.

4. Perform and interpret PE findings relevant to system and presenting symptoms that would enable the pharmacist determine appropriate medication therapy.

5. Determine the clinical status of patient through assessment of PE findings required for monitoring of medication therapy.

6. Retrieve and assess relevant laboratory and diagnostic tests to and determine the need for relevant PEs to make appropriate follow up plans.

7. Understand the relevance of these skills to pharmacy practice in order to develop therapeutic plans and to monitor response to therapy.
1.2.2: Obtain and evaluate relevant history from the patient, his/her chart, caregivers and other health care professionals.

1.2.4: Perform and interpret findings of relevant physical assessments that are required to determine appropriate medication therapy.

1.2.5: Complete an assessment of the patient's ability to take/use/administer his/her medications.

1.8.1: Determine the clinical status of the patient, including completing physical assessments required for monitoring of medication therapy.

1.2.3: Order, retrieve and assess relevant lab tests and diagnostic assessments.

1.6: Develop a care plan that addresses a patient's medication-therapy problems and priority health and wellness needs.

2.1. Communicate non-verbally and verbally with others.

3.3. Work collaboratively with the patient and his/her health care professionals to provide care and services that facilitate management of the patient's health needs.

6.1. Demonstrate a thorough understanding of the fundamental knowledge required of pharmacists and apply this knowledge in daily practice. 
macotherapy. Each session begins with a didactic lecture using a PowerPoint presentation, followed by demonstrations to provide students with the opportunity to practice. During the lecture, case scenarios with simulated patient charts are introduced, which are used to discuss medical terminology and to assist in the interpretation of the clinical status of the patient presented in the case. Subsequently, anatomy and PE methods and techniques are briefly explained (through the use of illustrations and videos) after which practical demonstrations are conducted. Students learn to use appropriate and relevant tools and equipment and practice these skills as a group under the supervision of the course instructors (physician, pharmacist) with ad-hoc collaborators (such as a nurse).

Students are assessed through both practical tests and written exams. Practical tests are conducted through the use of simulated patients in which student's ability to communicate, perform PE techniques and interpretation of findings are evaluated.

\subsubsection{The WCM-Q Health Assessment Curricula}

The WCM-Q medical program is a 6-year long integrated curriculum, with patient care as a core theme that spans the entire curriculum. Progressively, the students acquire the required knowledge, skills and attitudes to conduct patient interviews, health assessments, and provide individual patient care and exercise physicianship. Instructional methods are varied and include lectures, problem based discussions, seminars, case discussions and self-directed required readings. Simultaneously they build skills-based competencies through hands on clinical skills training, practice with simulated patients and task trainers, and real patient encounters throughout the clinical training at various clinical settings.

An anatomical system-based approach is used to deliver the entire curriculum content in which health assessment is embedded through the four years of the medical education, all including a comprehensive history taking, comprehensive PE, problem identification, development of a management plan including diagnostic tests and interpretation. The courses are delivered predominately by medical doctors and the students are assessed through written assignments, mostly using multiple-choice questions (MCQs), and clinical patient write-ups. The practical exams are mostly through objective structured clinical examinations (OSCEs), as well as directly observed real patient encounters.

\subsubsection{The UCQ Health Assessment Curricula}

A three-credit-hour health assessment course (namely Nursing 211) is delivered in one semester during the first nursing academic year. The course is delivered using a learner-centered approach that requires active participation by the nursing student in both lecture and laboratory environments.

The course utilizes a variety of learning resources, including lectures, assigned readings, videos, group discussions/activities, simulations, and interactive case studies. Laboratory sessions assigned for this course provide a simulated environment for the development of interviewing skills and the performance of focused and comprehensive 
PE. During laboratory sessions, nursing colleagues participate as laboratory partners, and a variety of equipment and technology such as high-low fidelity simulation, mannequins, heart and lung sound simulators, and various teaching models that provide life-like representations of the human body are used. Utilizing these resources students can experience the assessment of normal and abnormal/pathologic findings.

An anatomical system-based approach is used to deliver the course and includes interviewing and health history taking, approach to symptoms, and techniques for PE. The health assessment course is taught in parallel with pharmacology and the students' first nursing clinical practice courses. The course is delivered by an academic registered nurse only. Students are assessed through written exams, presentations, and OSCE as a practical assessment.

\subsection{Students' Self-Reported Training in Health Assessment}

\subsubsection{Students' Demographic Characteristics}

Only 81 students completed the questionnaire (39\% response rate) and the majority were females ( $\mathrm{n}=67,82.7 \%)$. Two-thirds of the students had been through clinical rotations for four months or more. About $66 \%$ of the participants were planning to work in secondary or tertiary health care settings in the future, and only a few preferred working in primary care settings. Table 2 provides details about the participants' demographic characteristics.

\subsubsection{Health Care Students' Perceived Training on a Variety of of Health Assessments and Disease Screening}

Students in the three disciplines reported having been trained in all the health assessments examined in the survey, although there were differences in where the training was delivered. As presented in Table 3, almost all participating students received train-

Table 2. Participant demographics and characteristics $(\mathrm{N}=81)$.

\begin{tabular}{|c|c|c|c|}
\hline \multicolumn{2}{|c|}{ Parameters } & $\mathrm{n}$ & Percentage \\
\hline \multirow{3}{*}{ Discipline } & Pharmacy & 35 & $43 \%$ \\
\hline & Medicine & 25 & $30.9 \%$ \\
\hline & Nursing & 21 & $26 \%$ \\
\hline \multirow{2}{*}{ Gender } & Female & 67 & $82.7 \%$ \\
\hline & Male & 14 & $17.2 \%$ \\
\hline \multirow{4}{*}{ Total duration of clinical placements } & Less than 1 month & 1 & $1.2 \%$ \\
\hline & $1-3$ months & 25 & $30.9 \%$ \\
\hline & 4 - 6 months & 25 & $30.9 \%$ \\
\hline & More than 6 months & 30 & $37 \%$ \\
\hline \multirow{4}{*}{ Preferred workplace after graduation } & Primary care & 6 & $7.4 \%$ \\
\hline & Secondary/Tertiary & 54 & $66.7 \%$ \\
\hline & Academia & 14 & $17.2 \%$ \\
\hline & Other (school, research, surgery related, etc.) & 7 & $8.6 \%$ \\
\hline
\end{tabular}


Table 3. Health care student's perceived training on variety of health assessments.

\begin{tabular}{|c|c|c|c|c|c|}
\hline Health Assessment & Discipline & $\begin{array}{l}\text { Training on } \\
\text { CAM n (\%) }\end{array}$ & P-value ${ }^{*}$ & $\begin{array}{c}\text { Training in CPs } \\
\mathrm{n}(\%)\end{array}$ & P-value \\
\hline \multirow{3}{*}{$\begin{array}{l}\text { BP measurement } \\
\qquad \mathrm{N}=100 \%\end{array}$} & Pharmacy & $34(100 \%)$ & \multirow{3}{*}{0.33} & $15(43 \%)$ & \multirow{3}{*}{$<0.01$} \\
\hline & Medicine & $24(96 \%)$ & & $18(72 \%)$ & \\
\hline & Nursing & $21(100 \%)$ & & $19(91 \%)$ & \\
\hline \multirow{3}{*}{$\begin{array}{l}\text { PR measurement } \\
\qquad \mathrm{N}=100 \%\end{array}$} & Pharmacy & $34(100 \%)$ & \multirow{3}{*}{0.11} & $7(21 \%)$ & \multirow{3}{*}{$<0.01$} \\
\hline & Medicine & $23(92 \%)$ & & $21(84 \%)$ & \\
\hline & Nursing & $21(100 \%)$ & & $19(91 \%)$ & \\
\hline \multirow{3}{*}{$\begin{array}{l}\text { Heart Sounds } \\
\qquad \mathrm{N}=98 \%\end{array}$} & Pharmacy & $33(97 \%)$ & & $3(9 \%)$ & \multirow{3}{*}{$<0.01$} \\
\hline & Medicine & $21(84 \%)$ & 0.15 & $22(88 \%)$ & \\
\hline & Nursing & $20(95 \%)$ & & $18(86 \%)$ & \\
\hline \multirow{3}{*}{$\begin{array}{l}\text { Blood Glucose Testing } \\
\qquad \mathrm{N}=90 \%\end{array}$} & Pharmacy & $34(100 \%)$ & & $16(46 \%)$ & \multirow{3}{*}{$<0.01$} \\
\hline & Medicine & $8(32 \%)$ & $<0.01$ & $13(52 \%)$ & \\
\hline & Nursing & $15(71 \%)$ & & $21(100 \%)$ & \\
\hline \multirow{3}{*}{$\begin{array}{l}\text { Urine Glucose Testing } \\
\qquad \mathrm{N}=68 \%\end{array}$} & Pharmacy & $30(88 \%)$ & & $0(0 \%)$ & \multirow{3}{*}{$<0.01$} \\
\hline & Medicine & $3(12 \%)$ & $<0.01$ & $8(32 \%)$ & \\
\hline & Nursing & $6(29 \%)$ & & $16(76 \%)$ & \\
\hline \multirow{3}{*}{$\begin{array}{l}\text { Blood Cholesterol Testing } \\
\qquad \mathrm{N}=41 \%\end{array}$} & Pharmacy & $13(39 \%)$ & & $4(12 \%)$ & \multirow{3}{*}{$<0.01$} \\
\hline & Medicine & $2(8 \%)$ & 0.02 & $5(20 \%)$ & \\
\hline & Nursing & $5(24 \%)$ & & $13(62 \%)$ & \\
\hline \multirow{3}{*}{$\begin{array}{l}\text { BMI Measurements } \\
\qquad \mathrm{N}=92 \%\end{array}$} & Pharmacy & $30(91 \%)$ & & $12(36 \%)$ & \multirow{3}{*}{0.12} \\
\hline & Medicine & $23(92 \%)$ & 0.39 & $15(60 \%)$ & \\
\hline & Nursing & $16(80 \%)$ & & $12(60 \%)$ & \\
\hline \multirow{3}{*}{$\begin{array}{l}\text { Waist Circumference } \\
\qquad \mathrm{N}=61 \%\end{array}$} & Pharmacy & $20(56 \%)$ & & $3(9 \%)$ & \multirow{3}{*}{0.01} \\
\hline & Medicine & $11(44 \%)$ & 0.53 & $7(28 \%)$ & \\
\hline & Nursing & $11(52 \%)$ & & $10(48 \%)$ & \\
\hline \multirow{3}{*}{$\begin{array}{l}\text { INR Testing } \\
\mathrm{N}=44 \%\end{array}$} & Pharmacy & $8(24 \%)$ & & $5(15 \%)$ & \multirow{3}{*}{0.01} \\
\hline & Medicine & $4(16 \%)$ & 0.58 & $9(36 \%)$ & \\
\hline & Nursing & $6(29 \%)$ & & $11(52 \%)$ & \\
\hline \multirow{3}{*}{$\begin{array}{l}\text { BMD Measurement } \\
\qquad \mathrm{N}=37 \%\end{array}$} & Pharmacy & $8(24 \%)$ & & $3(9 \%)$ & \multirow{3}{*}{0.01} \\
\hline & Medicine & $3(12 \%)$ & 0.46 & 7 (28\%) & \\
\hline & Nursing & $5(24 \%)$ & & $10(48 \%)$ & \\
\hline \multirow{3}{*}{$\begin{array}{l}\text { Used POC Instruments } \\
\qquad \mathrm{N}=89 \%\end{array}$} & Pharmacy & $30(88 \%)$ & & $19(54 \%)$ & \multirow{3}{*}{0.02} \\
\hline & Medicine & $15(60 \%)$ & 0.04 & $15(60 \%)$ & \\
\hline & Nursing & $16(76) \%$ & & 19 (91\%) & \\
\hline \multirow{3}{*}{$\begin{array}{l}\text { Used CVD Risk Calculators } \\
\qquad \mathrm{N}=75 \%\end{array}$} & Pharmacy & $32(94 \%)$ & & $11(32 \%)$ & \multirow{3}{*}{0.09} \\
\hline & Medicine & $6(24 \%)$ & $<0.01$ & $15(60 \%)$ & \\
\hline & Nursing & $6(29 \%)$ & & $8(38 \%)$ & \\
\hline
\end{tabular}

$\mathrm{N}=$ Percentage of all students who indicated receiving training in the specific health assessment, CAM = Campus, $\mathrm{CPs}=$ Clinical Placements, $\mathrm{BP}=$ Blood pressure, $\mathrm{PR}=$ Pulse rate, $\mathrm{BMI}=$ Body mass index, $\mathrm{INR}=$ International normalised ratio, $\mathrm{BMD}=$ Bone mineral density, $\mathrm{POC}=$ Point-of-care, $\mathrm{CVD}=$ Cardiovascular disease. ${ }^{*}$ Chi-square test, Level fo Significance was set at $\mathrm{p} \leq 0.05$. 
ing on blood pressure (BP) and pulse rate (PR) measurements on campus. There was no statistical difference among the three cohort of students. However, training in clinical placements was statistically different in these two health assessments $(\mathrm{p}<0.01$ for $\mathrm{BP}$ and $\mathrm{p}<0.01$ for PR). Pharmacy students reported less training during clinical rotations compared to medicine and nursing students (43\% vs $72 \%$ and $91 \%$ respectively for BP; $21 \%$ vs $84 \%$ and $91 \%$ respectively for PR). Similarly, pharmacy students received training on heart sounds primarily on campus rather than at clinical placements (97\% vs $9 \%$ ). The two other cohorts received training on heart sounds almost equally at clinical placements and on campus.

The proportion of students who received training on testing blood glucose, urine glucose and blood cholesterol were significantly different among the three student cohorts in both training sites $(\mathrm{p}<0.01$ for all; and $\mathrm{p}=0.02$ for blood cholesterol testing on campus). There was no statistical difference among the three cohorts in regards to training on Body Mass Index (BMI) measurements. Results also indicated that nursing students were significantly more likely to be trained on measuring waist circumference at clinical placements compared to medical or pharmacy students $(\mathrm{p}=0.01)$.

There was a statistically significant difference in the percent of students in each of the three cohorts who received training on International Normalized Ratio (INR) at clinical placements. A higher percentage of nursing students (52\%) than pharmacy (15\%) or medical (36\%) students were trained on INR testing.

There was a statistically significant difference in the percent of students who received training on the use of POC instruments at both settings ( $\mathrm{p}=0.04$ on campus and $\mathrm{p}=$ 0.02 during clinical placements). More pharmacy students received training on campus compared to nursing and medical students ( $88 \%$ vs. $76 \%$ and $60 \%$, respectively). However, at clinical placements, a greater proportion of nursing students received training on the use of POC instruments compared to medicine and pharmacy students (91\% vs. $60 \%$ and $54 \%$, respectively).

Pharmacy students were significantly more likely to receive training on the use of CVD risk calculators on campus than nursing or medicine students ( $94 \%$ vs. $29 \%$ and $24 \%$, respectively, $\mathrm{p}<0.01$ ). There was no significant difference in the proportion of each of the three cohorts being trained on the use of CVD risk calculators at clinical placements.

Overall, less than half of the students in all three colleges received training on blood cholesterol testing (41\%), INR testing (44\%) and Bone Mineral Density (BMD) measurement $(37 \%)$.

Figure 1 illustrates that overall pharmacy students received most of their health assessment training on campus. Although for some health assessments, training was received by students at both settings, on campus and during clinical placements ( $40 \%$ of BP measurement training, $43 \%$ of blood glucose testing training, and $43 \%$ for the use of POC instruments training). BMD and INR testing were the health assessments less frequently reported by the students as being taught, either on campus or at clinical placements ( $24 \%$ and $9 \%$ for BMD; $24 \%$ and $15 \%$ for INR testing, respectively). No 


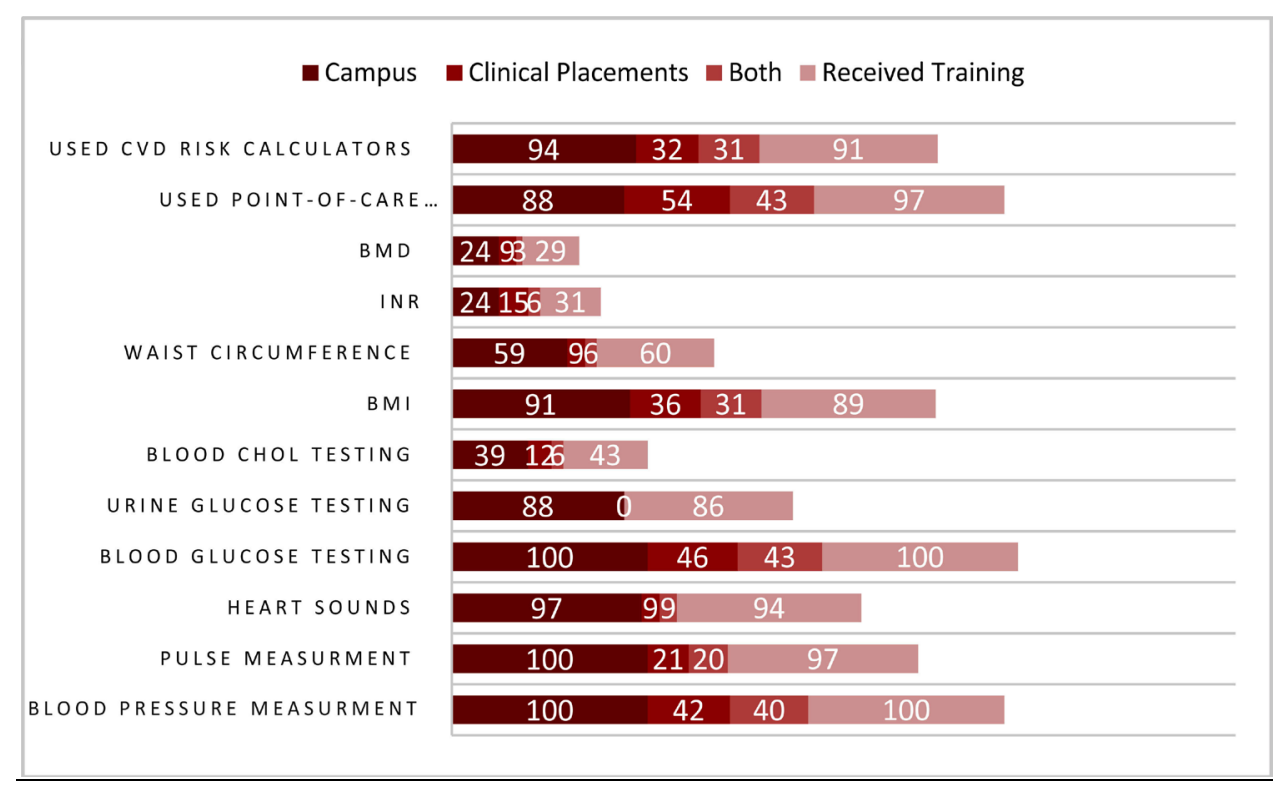

Legend: Campus: Students received training in classroom settings; Clinical Placements: Students received training during their clinical rotations; Both: Students received training at both settings (Campus and Clinical Placements); Received training: Students received training regardless of the setting.

Figure 1. Percentage of pharmacy students who indicated receiving health assessments training.

pharmacy students indicated having received training on urine glucose testing during their clinical placements.

As shown in Figure 2, most of the medical students received training on heart sounds, PR and BP measurement at both settings (72\%, 76\% and 68\%, respectively). Overall, only a small proportion of medical students indicated to have received training in BMD measurement, INR, blood cholesterol and urine glucose testing $(8 \%, 8 \%, 8 \%$ and $12 \%$, respectively).

Figure 3 illustrates that the majority of nursing students perceived having received training on blood glucose testing, heart sounds, PR and BP measurements, and the use of POC instruments at both settings (71\%, 86\%, 90\%, 91\% and 71\%, respectively).

\section{Discussion}

In the current study, we reviewed the health assessment curricula across three different professional degree programs, allowing content, teaching approaches and summative assessment activities to be compared. Then, we used information derived from a student survey to assess the students' perceived training on a variety of health assessments in an attempt to understand if any findings could be the result of differences in the curricula or the pedagogy used in the three professional programs.

Most similarities were observed within the pharmacy and nursing curricula. Both programs offer courses specific to health assessment which are integrated with other relevant courses that are delivered simultaneously. A difference however was noted in the timing of the delivery of health assessment content; which for pharmacy students is in their second year and for nursing students it is in their first year. The health assessment 


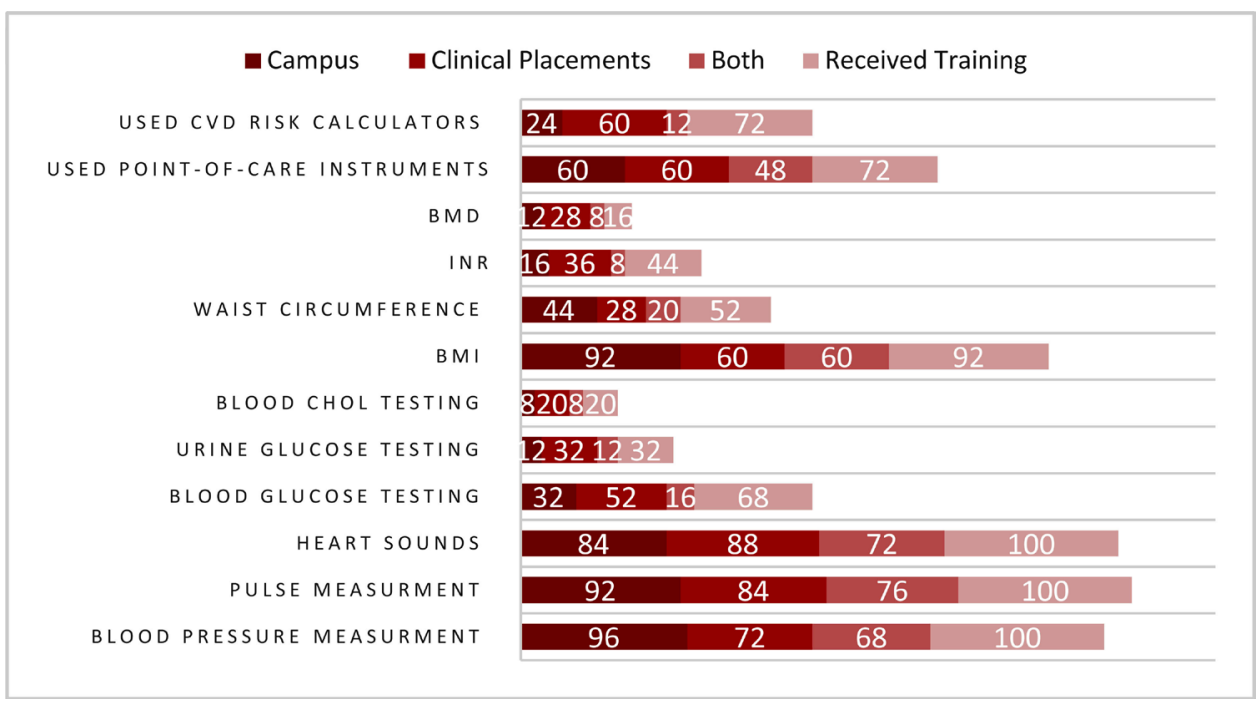

Legend: Campus: Students received training in classroom settings; Clinical Placements: Students received training during their clinical rotations; Both: Students received training at both settings (Campus and Clinical Placements); Received training: Students received training regardless of the setting.

Figure 2. Percentage of medical students who indicated receiving health assessments training.

\begin{tabular}{|c|c|c|c|}
\hline \multirow{2}{*}{\multicolumn{2}{|c|}{ USED CVD RISK CALCULATORS }} & Clinical Placements $\quad$ Both & Received Training \\
\hline & & \begin{tabular}{|llll}
29 & 38 & 19 & 48 \\
\end{tabular} & \\
\hline USED POINT-OF-CARE INSTRUME & NTS & 91 & 95 \\
\hline & $M D$ & \begin{tabular}{|llll}
24 & 48 & 19 & 52
\end{tabular} & \\
\hline & INR & $\begin{array}{llll}29 & 52 & 19 & 62\end{array}$ & \\
\hline WAIST CIRCUMFEREI & NCE & $\begin{array}{llll}52 & 48 & 29 & 71\end{array}$ & \\
\hline & BMI & $60 \quad 43$ & 91 \\
\hline BLOOD CHOL TESTI & ING & \begin{tabular}{|llll}
24 & 62 & 24 & 62
\end{tabular} & \\
\hline URINE GLUCOSE TESTI & ING & $\begin{array}{llll}29 & 76 & 29 & 7 t\end{array}$ & 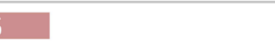 \\
\hline BLOOD GLUCOSE TESTI & ING & 100 & 71 \\
\hline HEART SOUN & NDS & 95 & 86 \\
\hline PULSE MEASURME & ENT & 100 & 100 \\
\hline BLOOD PRESSURE MEASURME & ENT & 100 & 91 \\
\hline
\end{tabular}

Legend: Campus: Students received training in classroom settings; Clinical Placements: Students received training during their clinical rotations; Both: Students received training at both settings (Campus and Clinical Placements); Received training: Students received training regardless of the setting.

Figure 3. Percentage of nursing students who indicated receiving health assessments training.

curricula in the medical program is quite different as health assessment is not taught specifically in one particular course or a sequence of courses, rather health assessment teaching and learning is embedded throughout the entire four years of the medical program.

The findings of the students' survey also served to highlight additional differences in the health assessment curricula among the three health disciplines, particularly in where the content is delivered. Pharmacy students indicated that they received most of 
their health assessment training on campus, either in the classroom or in a laboratory (simulated) setting, compared to nursing and medical students who reported their health assessment training was during clinical placements and through problem-based learning (PBL). These similarities can be the result of the synergy between the scope of practice of doctors and nurses [15]. Clinical placements are different for pharmacy students, as their clerkships include dispensing components that do not provide complementary learning to further develop health assessment skills.

Despite these differences, an important similarity in the pedagogical approaches used for delivering health assessment curricula was observed. In all disciplines, health assessment is taught utilizing a system-based approach and is integrated with other relevant courses (such as pharmacology in the nursing program, laboratory data and pathophysiology in the pharmacy program, and the examination of heart and lungs in the Cardiovascular and Respiratory organ systems units respectively, in the medicine program). The three degree programs build their students' knowledge-based competencies through lectures and required readings. With the exception of the medicine program in which students build on their health assessment skills from direct patient contact through early practical experiences, building skill-based competencies in the pharmacy and nursing programs rely on the use of laboratories appropriately equipped for PEs, using simulated patients, mannequins, and simulation equipment. The pharmacy program utilizes a variety of health professionals for delivering the health assessment course, including a doctor, pharmacist and ad-hoc nursing instructors. A study by Awaisu et al. indicated that students were satisfied with this collaborative instructional methodology and that this approach might improve student knowledge and ability. In this study students indicated gaining above average to excellent PE skills and understanding of the importance of learning these skills when the course was taught by physician-pharmacist collaboration compared to physician alone (75\% vs $42 \%$ and $83 \%$ vs $50 \%$, respectively) [16]. Another observed similarity is the aspect of student evaluations (mainly practical tests including OSCE) at the three colleges. Additionally, the topics included in patient assessment course in the pharmacy curricula are very similar to those covered in pharmacy programs in the US [17].

Although some students perceived having received limited training in certain health assessments, these findings must be interpreted with caution. For example, only a small proportion of medical students indicated to have received training in BMD measurement, INR, blood cholesterol and urine glucose testing. Considering that in medical school the health assessment curricula is mostly delivered through PBL tutorials and largely during clinical placements, it is possible that these findings are rather an indication that these health assessments are outside the medical students' scope of training during their clinical placements. Similar findings have been illustrated in other studies comparing curricula among health-related degree programs [18].

Pharmacy students reported limited training in some health assessments during clinical placements (e.g., heart sounds, waist circumference measurement and urine glucose testing), again probably because currently these are not an everyday practice for 
pharmacists. Health assessment training during experiential education is an area that needs to be addressed in the pharmacy curricula, particularly for health assessments that are considered vital when monitoring pharmacotherapy outcomes, such as INR testing, BP and PR measurements. Other studies with pharmacy students have reported similar findings, where only a small proportion of students indicated they received instruction on PE and that they rarely or never had the opportunity to use those skills at their internship sites [19].

This study has several limitations. The most important to highlight is the self-reporting aspect of the curricular review, and the potential for variability in the students' interpretation of the health assessment training definitions. Students' experiences and recall of what they have learnt is helpful, although we emphasize that the numbers are small and thus the findings cannot be seen as statistically rigorous. However, the findings have provided some data that the individual colleges could use in curricular review and redesign.

Forming competent pharmacists for future primary care multidisciplinary roles requires proper conduct of health assessments and yet this study shows that for a number of fundamental skills, although covered in the pharmacy curricula, students perceive there is insufficient training for them to achieve mastery. Efforts should be made to incorporate consistent experiential opportunities for pharmacy students during clinical placements. The study may also be able to raise awareness of the benefits of collaboration, and the future design of inter-professional education, particularly in health assessments that are likely to be within the scopes of practice of all three disciplines as we move towards achieving Qatar's public health strategy which is inherently collaborative.

\section{Conclusion}

This study has identified a close alignment between each of the health discipline's scope of practice and the health assessment content taught in each individual program. Improvement in the experiential component of the pharmacy health assessment curricula is needed. The findings of this study also suggest that health assessment training of pharmacy, medical and nursing students lends towards collaborative learning in preparation of future collaborative roles in primary care.

\section{References}

[1] American Public Health Association (APHA) (2016) The Role of the Pharmacist in Public Health.

http://www.apha.org/policies-and-advocacy/public-health-policy-statements/policy-databa se/2014/07/07/13/05/the-role-of-the-pharmacist-in-public-health

[2] Bell, H.S., Albano, C.B., Kennedy, K.B., et al. (2014) Report of the 2013-2014 AACP Standing Committee on Advocacy: Improving Advocacy through the Use of Implementation Science Concepts and Frameworks. The American Journal of Pharmaceutical Education, 78, S20. https://doi.org/10.5688/ajpe7810S20

[3] Lai, E., Trac, L. and Lovett, A. (2013) Expanding the Pharmacist's Role in Public Health. Universal Journal of Public Health, 1, 79-85. 
[4] Pharmaceutical Services Negotiating Committee, National Pharmaceutical Association, Royal Pharmaceutical Society of Great Britain, Pharmacy Health Link (2016) Public Health: A Practical Guide for Community Pharmacists. http://psnc.org.uk/wp-content/uploads/2013/07/public health book all.pdf

[5] Longe, L.R. and Calvert, J.C. (1997) Physical Assessment and the Clinical Pharmacist. Drug Intelligence \& Clinical Pharmacy, 11, 200-203.

[6] Jones, R.A. (2003) Patient Assessment and the Pharmaceutical Care Process. In: Jones, R.M. and Rospond, R.M., Eds., Patient Assessment for Pharmacy Practice, Lippincott Williams \& Wilkins, Baltimore, 2-8.

[7] Schiff, G., Klass, D., Peterson, J., Shah, G. and Bates, D. (2003) Linking Laboratory and Pharmacy: Opportunities for Reducing Errors and Improving Care. Archives of Internal Medicine, 163, 893-900. https://doi.org/10.1001/archinte.163.8.893

[8] Longe, R.L. and Calvert, J.C. (1994) Physical Assessment: A Guide for Evaluating Drug Therapy. Applied Therapeutics Inc., Vancouver.

[9] Association of Faculties of Pharmacy of Canada (AFPC) (2010) Educational Outcomes for First Professional Degree Programs in Pharmacy (Entry-to-Practice Pharmacy Programs) in Canada. https://www.afpc.info/sites/default/files/AFPC\%20Educational\%20Outcomes.pdf

[10] Accreditation Council for Pharmacy Education (ACPE) (2011) Accreditation Standards and Guidelines for the Professional Program in Pharmacy Leading to the Doctor of Pharmacy Degree. http://www.acpe-accredit.org/standards/default.asp

[11] American Association of Colleges of Pharmacy (AACP) (2013) Center for the Advancement of Pharmaceutical Education (CAPE). Educational Outcomes 2013. http://www.aacp.org/documents/CAPEoutcomes071213.pdf

[12] Jones, M., Gokun, Y., Cain, J. and Romanelli, F. (2014) Physical Examination in US Pharmacy Curricula. Currents in Pharmacy Teaching and Learning, 6, 340-347. http://dx.doi.org/10.1016/j.cptl.2014.02.013

[13] Porter, A.C. (2006) Curriculum Assessment. In: Green, J.L., Camilli, G. and Elmore, P.B., Eds., Handbook of Complementary Methods in Education Research, American Educational Research Association, Washington DC, 141-159.

[14] National Association of Pharmacy Regulatory Authorities (NAPRA) (2007) Professional Competencies for Canadian Pharmacists at Entry to Practice. 2nd Revision.

http://napra.ca/content Files/Files/Entry to Practice Competencies March2007 final ne w layout 2009.pdf

[15] Ladhani, Z., Stevens, F.J. and Scherpbier, A.J. (2014) Does Community Health Care Require Different Competencies from Physicians and Nurses? BMC Medical Education, 14, 1. http://dx.doi.org/10.1186/1472-6920-14-1

[16] Awaisu, A. and Pawluk, S. (2015) Patient Assessment Teaching and Learning in Undergraduate Pharmacy Curriculum: Students' Perspective of a Pharmacist-Physician Instructional Strategy. Pharmacy Education, 15, 27-130.

[17] Spray, J.W. and Parnapy, S.A. (2007) Teaching Patient Assessment Skills to Doctor of Pharmacy Students: The TOPAS Study. American Journal of Pharmaceutical Education, 71, Article Number: 64. https://doi.org/10.5688/aj710464

[18] Lloyd, H., Hinton, T., Bullock, S., et al. (2013) An Evaluation of Pharmacology Curricula in Australian Science and Health-Related Degree Programs. BMC Medical Education, 13, 153. http://dx.doi.org/10.1186/1472-6920-13-153

[19] Bolesta, S., Trombetta, D.P. and Longyhore, D.S. (2011) Pharmacist Instruction of Physical Assessment for Pharmacy Students. American Journal of Pharmaceutical Education, 75, Article Number: 29. http://dx.doi.org/10.5688/ajpe75229 
Submit or recommend next manuscript to SCIRP and we will provide best service for you:

Accepting pre-submission inquiries through Email, Facebook, LinkedIn, Twitter, etc.

A wide selection of journals (inclusive of 9 subjects, more than 200 journals)

Providing 24-hour high-quality service

User-friendly online submission system

Fair and swift peer-review system

Efficient typesetting and proofreading procedure

Display of the result of downloads and visits, as well as the number of cited articles

Maximum dissemination of your research work

Submit your manuscript at: http://papersubmission.scirp.org/

Or contact health@scirp.org 